\title{
Atypical Presentation of Temporal Dermoid Cyst: Case Report
}

\section{Apresentação atípica de cisto dermoide temporal: caso clínico}

\author{
Sérgio Gonçalves da Silva Neto ${ }^{1}$ Thiago Martins ${ }^{1}$ Leonardo Moura ${ }^{1}$ Clemar Correa $^{2}$ \\ Wellingson Paiva ${ }^{2}$ Hector Navarro ${ }^{2}$ Manoel Jacobsen Teixeira ${ }^{3}$
}

\footnotetext{
1 Neurosurgery Resident Hospital das Clínicas, São Paulo Medical School, Universidade de São Paulo (HC-FM-USP), São Paulo, SP, Brazil

2 Functional Neurosurgery Department, Psychiatry Institute, HC-FMUSP, São Paulo, SP, Brazil

${ }^{3}$ Department of Neurosurgery, Universidade de São Paulo, São Paulo, SP, Brazil
}

\begin{abstract}
Address for correspondence Sérgio Gonçalves da Silva Neto, MR, São Paulo Medical School, Universidade de São Paulo (HC-FM-USP), São Paulo, SP, Brazil (e-mail: sgsnnc@gmail.com).
\end{abstract}

Arq Bras Neurocir 2015;34:317-320

\begin{abstract}
Dermoid account for $0.04-0.06 \%$ of intracranial tumors. The rupture of these slowgrowing lesions are a rare event, generally taking place spontaneously. Their presentation are clinically variable according to cyst topography and integrity. Surgery remains

Keywords

- dermoid cyst

- seizures

- brain tumor

\section{Resumo}

Palavras-chave

- cisto dermoide

- crise convulsiva

- tumor cerebral the first-line therapy and gross total resection should be attempted if feasible. We report on a case of a 22-year-old male with a 2-year history of seizures and cognitive impairment and a temporal mesial dermoid cyst successfully treated with gross total resection microsurgery.

Os Cistos dermoides compreendem $0,04-0,06 \%$ dos tumores intracranianos. É uma lesão de crescimento lento, e sua ruptura é um evento raro e espontâneo. A variabilidade clínica vai de acordo com a topografia do cisto e sua integridade. A cirurgia continua a ser a terapia de primeira linha, e a ressecção total é a opção sempre que for possível. Os autores relatam um caso de paciente com 22 anos de idade com histórico de 2 anos de convulsões e comprometimento cognitivo e diagnosticado com um cisto dermoide mesial temporal, tratado com sucesso com ressecção microcirúrgica.
\end{abstract}

\section{Introduction}

Dermoid and epidermoid cysts are benign that become neurenteric cysts due to errors during gastrulation. In dermoid cysts, this occurs between the third and fifth week of the embryonic period, with the inclusion of heterotopic elements of the ectoderm during the closure of the neural tube. Its contents include hair and hair follicles, sebaceous glands and sweat. ${ }^{1,2}$ Dermoid cysts account for 0.04 to $0.06 \%$ of intracranial tumors, with typical location in the midline of the posterior fossa and predominance in females. These cysts are sometimes associated to Klippel-Feil syndrome. In received

May 9, 2013

accepted

August 7, 2015

published online

October 13, 2015
DOI http://dx.doi.org/

10.1055/s-0035-1564693. ISSN 0103-5355.
Copyright $\odot 2015$ by Thieme Publicações License terms

Ltda, Rio de Janeiro, Brazil 


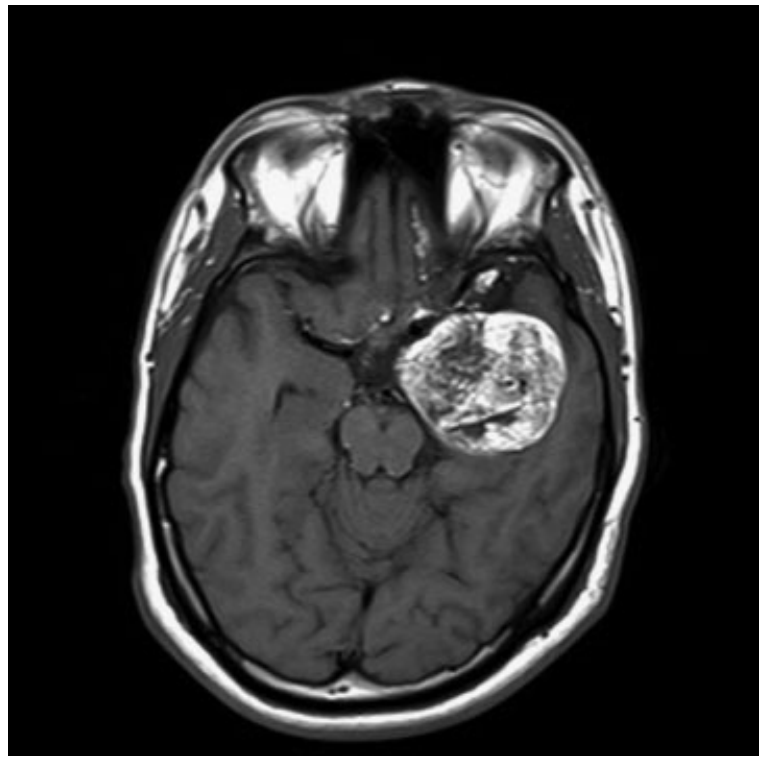

Fig. 1 BRAIN MRI, T1 weighted sequence with temporal lesion well delineated, heterogeneous, predominance of increased signal.

parallel with epidermoid cysts, dermoid cysts are more frequently found as intracranial lesions than spinal lesions, and usually as solid tumors, affecting adolescents and young adults (mean age 15-16). ${ }^{1-3}$

\section{Clinical Presentation and Diagnosis}

The dermoid cyst is a slow-growing lesion, through the exfoliation of epithelial cells and secretion of the sebaceous glands. There seems to be a relationship between age and growth and rupture, probably due to a hormonal mechanism in adolescents. ${ }^{4}$ It is manifested clinically when the size of

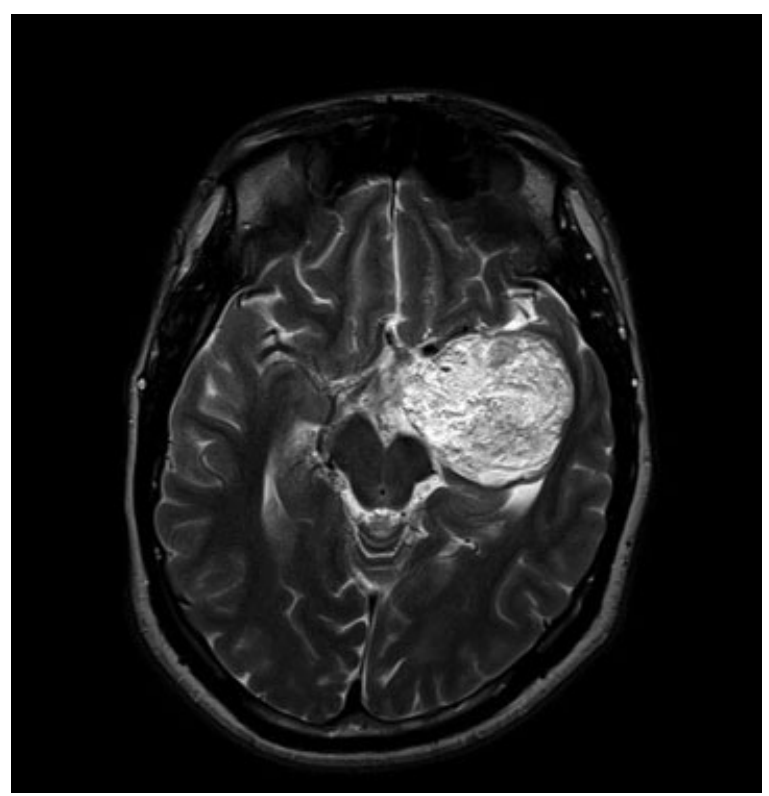

Fig. 2 BRAIN MRI RM T2 weighted sequence with temporal lesion well delineated, heterogeneous, predominance of increased signal.

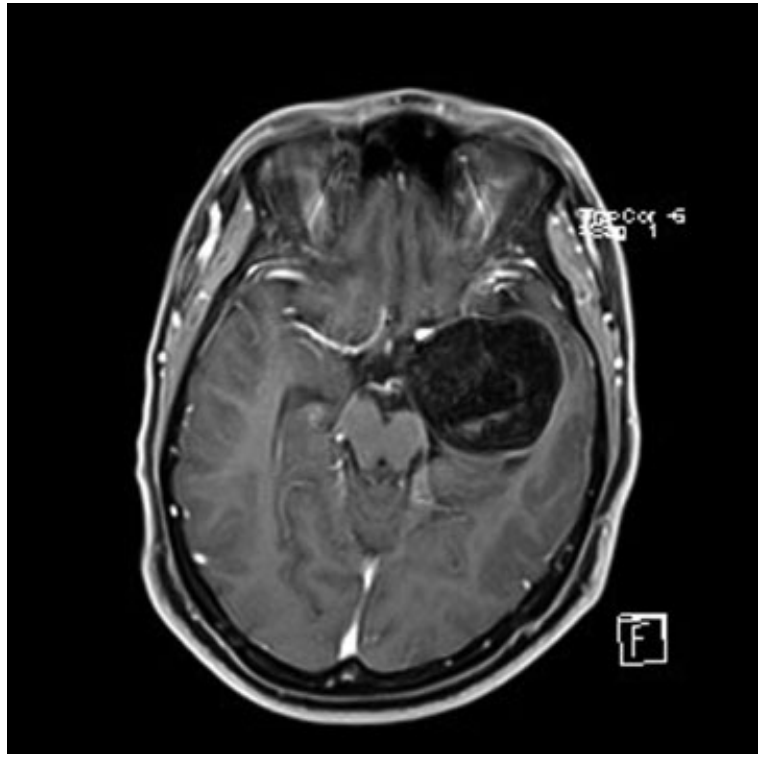

Fig. 3 BRAIN MRI T1GD weighted sequence with low contrast enhancement and evidence of a cystic content.

the cyst causes the compression of surrounding structures, when there is a rupture of the cyst (aseptic meningitis of Mollaret), or when it is infected. Symptoms include headache, nausea, vomiting, cerebellar syndrome, cranial nerve deficit, paresis, seizures, signs of meningism, and fever. These vary with the topography of the lesion, presence of breakage and/or infection of their contents. ${ }^{1,4,5}$

Upon physical examination, it is important to search for dermal sinuses, which may be associated with underlying dermoid cysts (e.g., dermal occipital sinus and cerebellar; spinal dysraphism dermoid cyst and Spinalis dermoid cyst), which, for being in contiguity, constitute a doorway for infection and formation of abscesses in the cysts. Neuroimaging tests, especially the computed tomography (CT) scan and magnetic resonance imaging (MRI) help in the diagnosis. In a skull CT, dermoid cysts appear as very dense lesions without iodized contrast uptake. In RNM, on the other hand, they appear as heterogeneous lesions with hypersignal in T1WI and T2WI. This is explained by their high cholesterol content without contrast uptake in T1GD. ${ }^{1,5,6}$

When there is suspicion of rupture of the cyst and/or meningism during physical examination, the specialist must conduct the cerebrospinal fluid analysis. Mollaret's aseptic meningitis evolves with osteoblasts at 26\% predominance of lymphocytic and high protein concentration on CSF. ${ }^{1,5}$

\section{Case Report}

C.A.P, male, 22 years old, previously healthy, from the state of Bahia. Referred to Neurosurgery outpatients service/ HCFMUSP with a 2 years history of intermittent episodes of partial seizures in the right upper limb and progressive memory loss, culminating in December 2012 with generalized tonic-clonic seizures. General physical examination: without notable changes neurological exam: alert and 


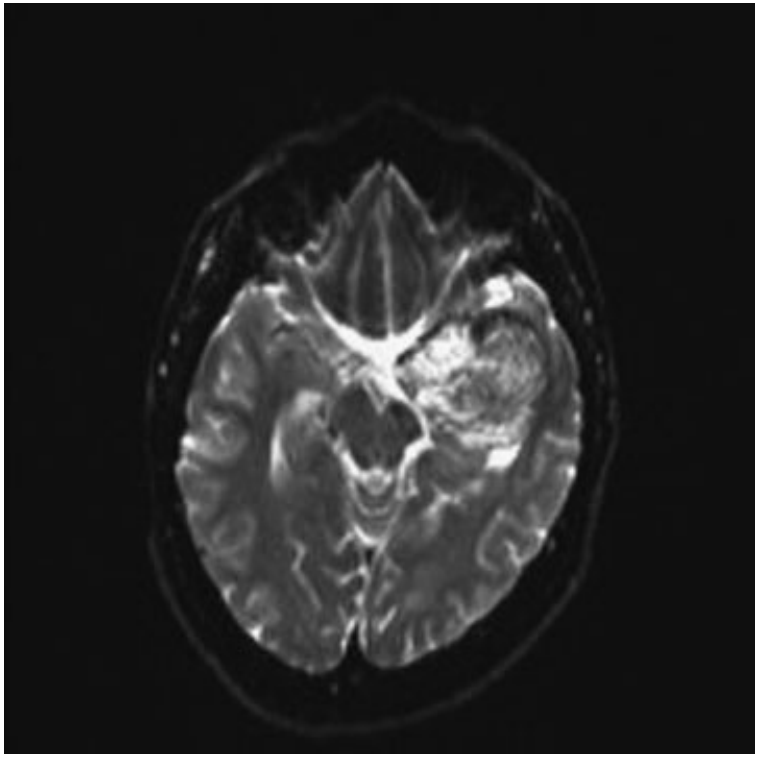

Fig. 4 BRAIN MRI DWI sequence with signs suggestive of rupture of cystic content to the sub-arachnoid space.

oriented. No gait impairment, normal muscular strength, sensitivity, ocular mobility, normal Funduscopic examination.

Neuroimaging exams revealed a left temporal lesion suggestive of dermoid cyst ( - Figs. 1-4). In June 2013, the patient was submitted to surgery: left temporal craniotomy and microscopic total tumor resections. During surgical planning, the authors took into account the position of the left middle cerebral artery (-Fig. 5). On the immediate post op the patient evolved without any clinical or radiological complications (as seen on -Fig. 6). In the 4th post-operative, patient evolved with symptoms of Meningitis, and after lumbar CSF analysis was confirmed (pattern of aseptic meningitis), the patient remained hospitalized for 14 days for antibiotic therapy. Discharged without complaints, during the 1 st month follow-up the patient denied new episodes of seizures.

The anatomical and pathological study of the surgical piece confirmed dermoid cyst diagnosis.

\section{Discussion}

Until today, surgery aiming a total resection is still the most appropriate conduct when facing a dermoid cyst, and should always be attempted without rupturing the capsule to reduce the chance of local recurrence or aseptic meningitis. However, total resection is not always possible because these lesions can be usually related with important neurovascular structures. $^{1,7}$

In the case in question, despite the atypical location, characteristic neuroimaging examinations allowed bringing the chance of dermoid cyst, corroborated by the anatomical and pathological study. ${ }^{1,7}$
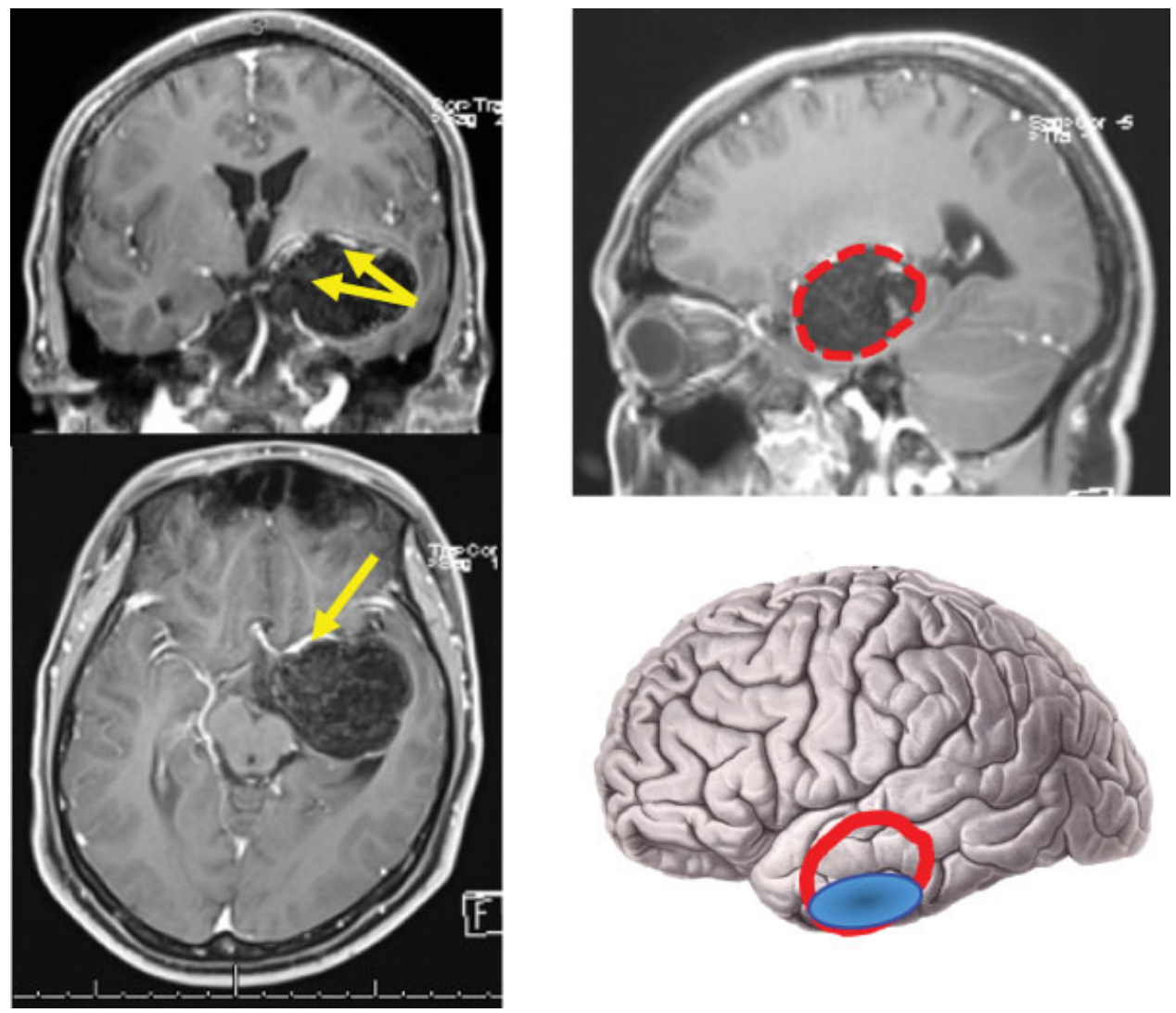

Fig. 5 Surgical planning taking into account the displacement of the left middle cerebral artery and the surgical relation with the middle and inferior temporal gyrus. 


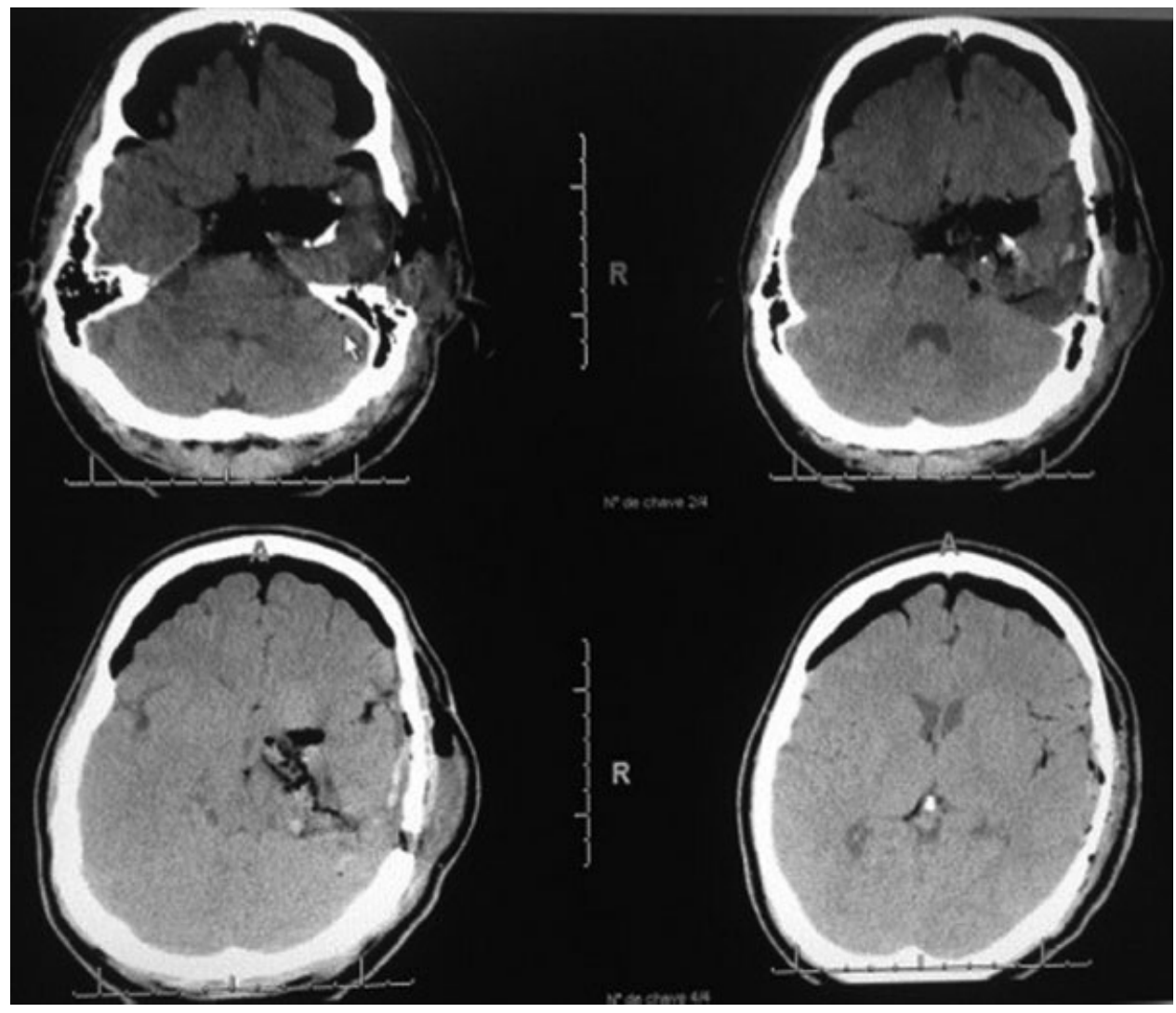

Fig. 6 Post operative brain CT.

\section{References}

1 Hassaneen W, Sawaya R. Epidermoid, dermoid and neuro- enteric cysts. In: Winn HR (ed). Youmans neurological surgery. Philadelphia: Elsevier Saunders; 2011: $1523-1528$

2 Xu XL, Li B, Sun XL, Li LQ, Ren RJ, Gao F. [Clinical and pathological analysis of 2639 cases of eyelid tumors]. Zhonghua Yan Ke Za Zhi 2008;44(1):38-41

3 Miyagi Y, Suzuki SO, Iwaki T, Ishido K, Araki T, Kamikaseda K. Magnetic resonance appearance of multiple intracranial epidermoid cysts: intrathecal seeding of the cysts? Case report. J Neurosurg 2000;92(4):711-714
4 Goyal N, Sharma MS, Gurjar H, Mahapatra AK. Multicentric intracranial epidermoid or epi/dermoid cysts? Acta Neurochir (Wien) 2012;154(7):1285-1286

5 Gumerlock MK. Epidermoid, dermoid, and neurenteric cysts in youmans neurological surgery. 5th ed. Philadelphia: W.B. Suanders; 2004:1223-30

6 Mehta MP, Chang SM, Vogelbaum MA, Guha A. Principles \& Practice of Neuro-Oncology: A Multidisciplinary Approach. Dermos Medical 2011:2880-2893

7 Park SK, Cho KG. Recurrent intracranial dermoid cyst after subtotal removal of traumatic rupture. Clin Neurol Neurosurg 2012;114(4):421-424 